\title{
To improve the contact adaptability of mechanical roof support
}

\author{
$N$. Babyr, K.Babyr \\ Saint-Petersburg Mining University, St Petersburg, Russia
}

\begin{abstract}
The article proposes a constructive technical solution to increase the contact adaptivity of the mechanical roof support. The developed solution of the mechanized support section is able to adapt to changing mining and geological conditions in the process of excavation of the mining pillar, which increases the efficiency and safety of coal excavation in the longwall.
\end{abstract}

\section{Introduction}

In the coal industry, $3 / 4$ of the coal volume is extracted by underground mining and is accounted for by the longwall. The rate of coal mining is constantly increasing, and the reserves of coal seams with favorable conditions for excavation are rapidly decreasing, respectively, coal seams with difficult mining and geological conditions are involved in the mining process. The presence of weak, as well as heavy, difficult to manage, weak watered soils, undulating hypsometry, irregularities in the bedding, increased gas content - this is not a complete list of the mining and geological factors that complicate coal mining $[1,13]$. However, not only complex mining and geological conditions affect the sustainable and efficient mining process. It has been established that cyclic force interactions of the roof support section with roof rocks negatively affect the condition of the roof rocks and, as a consequence, cause its efflorescence and delamination, which leads to roof «trampling» [2]. Therefore, improving the contact adaptivity, in particular, improving the design of mechanical roof support sections, and searching for new technical solutions for their implementation have been and remain relevant.

\section{Materials and Methods}

The effectiveness of interaction between the mechanical roof support and the rocks of the immediate roof and the soil in the working face depends on both the mining and geological conditions and the range of their variability, in which the section of the mechanical roof support works, and on the parameters of the section of the support itself.

Therefore its operating characteristics should be formed in accordance with these conditions. However, creating a machine for each specific face is certainly not rational, so to improve the stability of the process of controlling rock pressure in complex mechanized drifts, it is necessary to develop adaptive sections of mechanized roof support [3, 12], which will provide:

- increased uniformity of pressure distribution along the entire length of the slab 
contact area with the roof, contributing to increased stability of the roof control process;

- moving of the mechanical roof support section with fixed contacts of spacers with the roof and the soil; mining faces.

- ensuring stability and safety of the coal mining process in complex mechanized

The need to develop adaptive sections of mechanized roof supports (Fig. 1) that change in specific mining and geological conditions was pointed out by many well-known researchers, specialists and designers $[4,5]$.

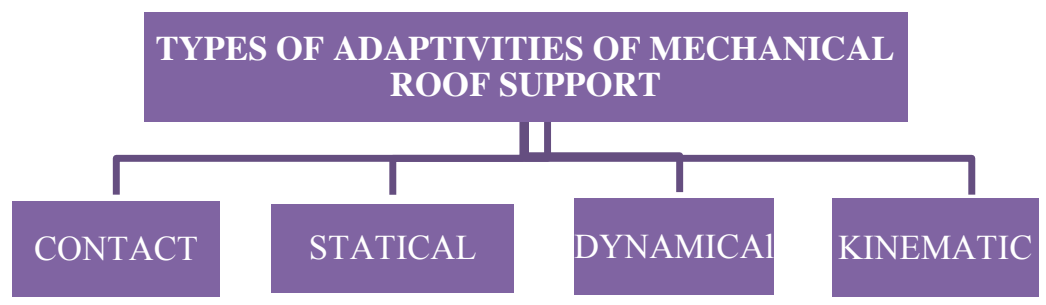

Fig. 1 - Types of adaptivities of mechanical roof support

However, the researchers paid less attention to contact adaptivity, which is of primary importance in comparison with statical, kinematical and dynamical adaptivity, since the technical solutions to reduce the loads on the immediate roof depend on its values.

Scientists have attempted to create contact-adaptive mechanical roof support that reduce roof trampling, such as pneumatic balloon roof supports (the term roof "trampling" is well known and characterizes the process of cyclic loading and unloading of lateral rocks when moving sections of the mechanical roof support, which causes stability failure).

The development of pneumatic cylinder fasteners marked the beginning of the development of new technical level fasteners $[6,10,14]$. The contact-adaptive sections of mechanical roof support allow to increase the supported area of contact between the sections of mechanical roof support and the roof and to improve the overlap adherence to the roof rocks. Such devices are described in detail in the technical literature $[7,8]$ and for convenience of analysis they should be divided into four groups:

1. Different types and types of canopies;

2. Pneumatic balloon roof supports;

3. Application of soft casings;

4. Unloading fasteners.

There are various designs of pneumatic cylinder fasteners. One of the types of devices that allow increasing the effective contact area and thereby increase the adaptive properties of the sections of mechanized fasteners. These developments belong to scientists Rakhutin V.S., Fedorenko E.A. [9] and others, and represent various applications of soft shells made of rubber cord by vulcanization method.

The technical solution is interesting because it improves the adaptability (adaptability) of the roof support to unevenness of the ground and the roof due to the fact that the upper 1 and lower 2 supports are interconnected by a bellows 4 made in the form of rubber-cord diaphragms 5 (Fig. 2). Moreover, the rubber-cord diaphragms 5 are deflected and compressed between the shells. After the initial spreading, the upper 1 and lower supports 2 are set relative to each other at any angle due to the absence of a rigid connection. The angle is determined by the size of irregularities in the soil and the bed roof. 


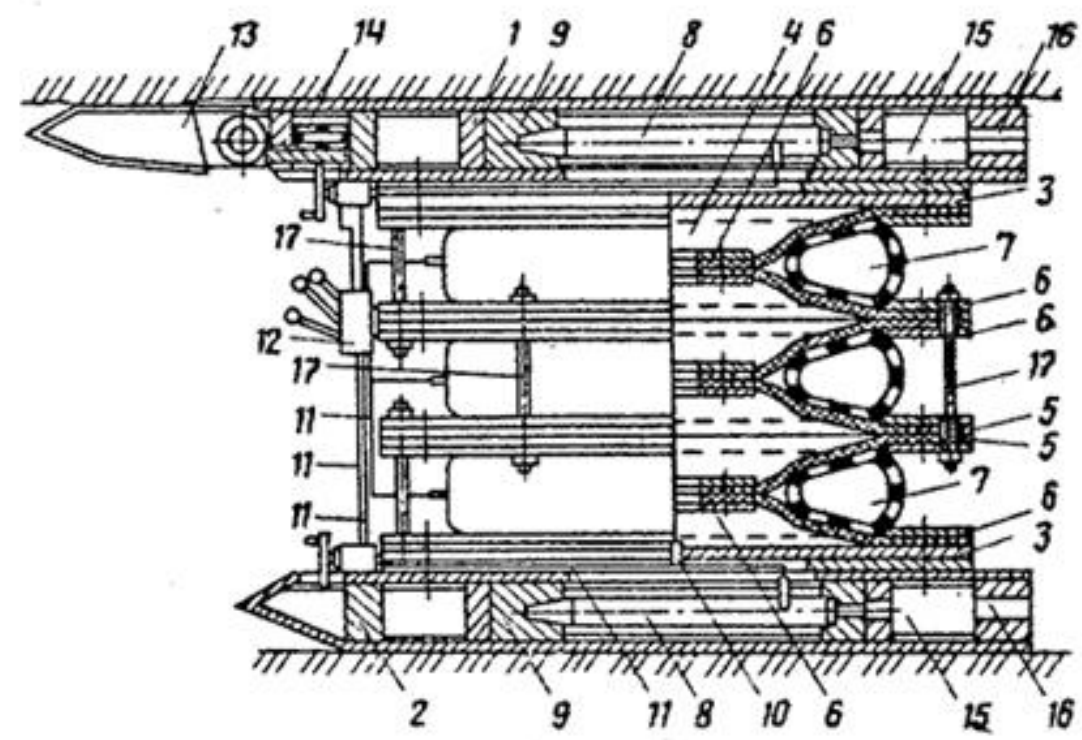

Fig. 2. Pneumatic cylinder mount, where 1, 2 - upper and lower supports; 3 - gasket; 4 - bellows; 5 rubber-cord diaphragm; 6 - metal ring; 7 - toroidal pneumatic shells; 8 - pneumatic mover; 9 - rotary cage; 10 - socket; 11 - piping; 12 - control panel; 13 - visor; 14 - pneumatic cylinder; 15 - channels; 16 - chambers; 17 - rods.

However, in spite of all the advantages of pneumatic barrier supports in comparison with the known designs of hydroficated roof supports, a number of factors limiting their further widespread use have been noted, such as:

- the large dimensions in comparison with hydraulic;

- the need to fill the casings with compressed air after each cycle of movement;

- dependence of the value of the initial spreading on the air pressure in the mine network.

In this connection the question arose about the creation of completely new constructive and technical solutions of contact adaptive sections of mechanized supports - supports of a new technical level.

\section{Results and discussion}

The scientific team of the Mining University Department of Mechanical Engineering propose the develop of mechanized roof support with supporting and guiding beams [11] (Fig. 3) in which the overlap section is made with a longitudinal groove open to the roof, in which the support beam 10 is mounted with the possibility of moving it with a hydraulic jack 3 pivotally connected to the overlap 4, to the step of movement of the support section $\mathrm{h}$, with the hydraulic cartridge 12 , mounted on the portal 4 , through the intermediate bearing trolley 14 overlap rests on the support beam 10 .

The technical result is achieved by the fact that the overlap of the section 4 is made with a longitudinal slot open to the roof, in which the support beam 10 is mounted with the possibility of moving it with a hydraulic jack 3 pivotally connected to the overlap, at a step of moving the section of the roof support, with the hydraulic cartridge, fixed on the portal 15 , through the intermediate bearing carriage 14 the slab rests on the supporting beam 10 , ensuring the motion of the section immobility of contact of the supporting beam with the 
roof, the beam is pressed to the roof, the roof is supported, the friction force of the slab against the roof and the movement of themechanical roof support section is reduced.

a)

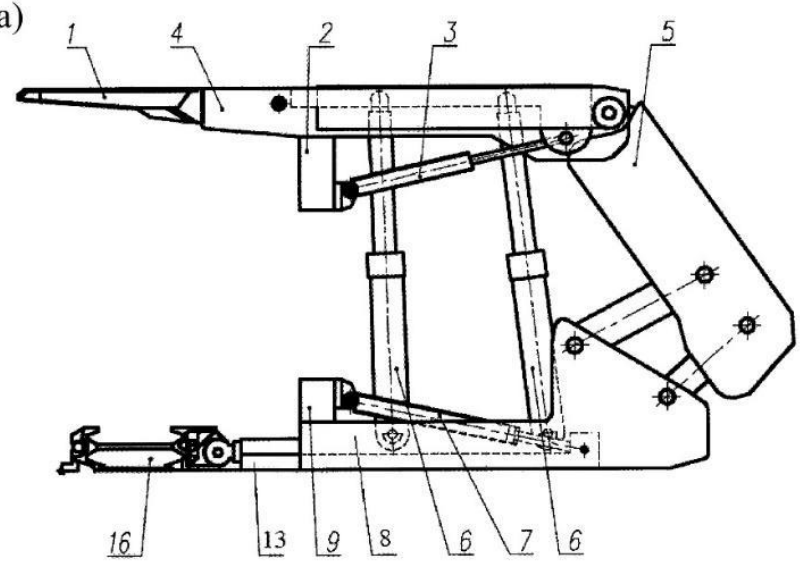

б)

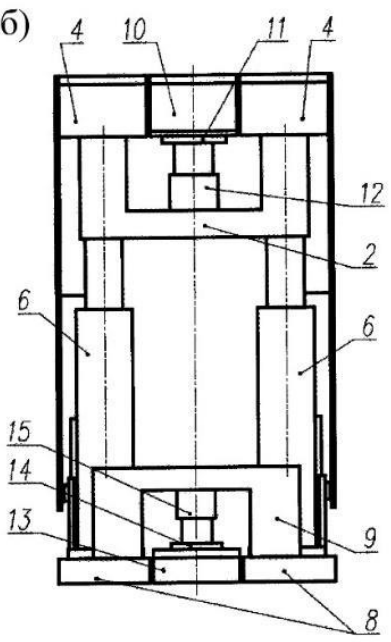

B)

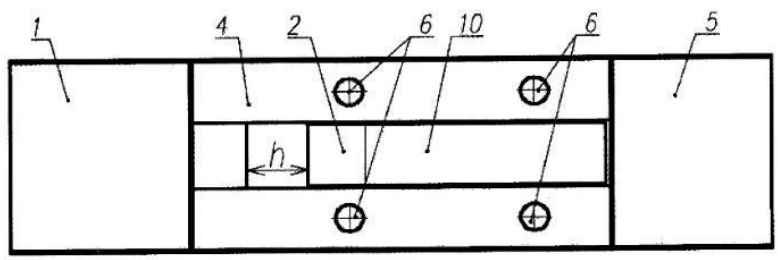

Fig. 3. Mechanized roof support: a - general view; b - front view, where 1 - canopy; 2 - portal on the slab; 3 - hydraulic jack on the slab; 4 - slab (topside); 5 - section's slide guard; 6 - hydraulic struts; 7 hydraulic jack moving on the base; 8 - section base; 9 - portal on the base; 10 - support beam; 11 sliding carriage along the base beam; 12 - hydraulic cartridge along the slab; 13 - guide beam; 14 sliding bearing carriage along the guide beam; 15 - hydraulic cartridge of compensating device; 16 bottom-hole scraper conveyor; $\mathrm{h}$ - step of guide beam movement.

The mechanized roof support consists of the overlap with the canopy 1 and portal 2, supporting beam 10, which is connected to the portal 2 by a hydraulic jack, through the hydraulic jack 3 with a guide beam, which is hinged at the other end to the stock of the downhole scraper conveyor 16.

The support beam 10 is installed in the slab groove with the possibility of moving at least by the section movement step $h$. The backfill fence is hinged to the slab 4 and to the base of the support section 8 . The slab 4 is supported on the base 8 by struts. Supporting beam 10 through the sliding bearing carriage 14 with a hydraulic cartridge 15 is based on the portal of the overlap 2 of the shielding section.

Mode of moving section carry out at the transfer of compensatory spreading from the base of the section 8 to the guide beam 13 and from the slab (top) 4 to the support beam 10 is set by adjusting the working fluid pressure in the compensatory hydraulic unit 15 and the hydraulic unit on the slab 12: at full compensation of the hydraulic struts spreading force 6 , the slab (topdeck) 4 breaks the contact with the roof, which provides the mode of moving the roof support section with breaking the contact with the roof; when compensating the force of hydrostocks 6 to the level of the designated support of the slab (overhead) 4 in the roof, carried out by a known method, the movement of the section is carried out in the mode with active or passive support and, in case of weak rocks of the immediate roof, the level of support of the slab (overhead) 4 in the roof can be adjusted by 
changing the pressure in the hydraulic unit for the slab 12 and hydraulic unit for the compensating device 15 , which provides a mode of movement with an adjustable support.

\section{Conclusion}

To improve the stability of the process of controlling rock pressure and, consequently, to increase the stability of the technological process of coal mining in the long complexmechanized stope faces of coal mines, the authors attempted to create a roof new technical level - contact-adaptive roof supports.

The proposed technical solution provides the following: the roof;

- immobility of contact of the support beam with the roof - by pressing the beam to

- support of the roof;

- reduction of friction force of the roof slab against the roof;

- walking shifting of the support section with raising of the front part of the foundation above the bedrock with active or passive support of the overlap into the roof;

-moving section movement with adjustable backing, or with a break in contact with the roof depending on the mining and geological conditions and the strength properties of the soil and the immediate roof, excluding "trampling" of the roof.

\section{References}

1. N. Babyr, A. Korolev, T. Neupokoeva. Enhancement of powered cleaning equipment with the view of mining and geological conditions IOP: Earth and Environmental Science 194 (2018).

2. I.V. Antipov. Geomechanical and technological basis for the creation of a new level of fasteners for thin gentle bed cleaning faces: an abstract by Doctor of Technical Sciences: 05.15.02. - Donetsk (1996).

3. V. Gabov, D. Zadkov, N. Babyr, A. Stebnev, V. Buevich. Adaptation of a section of mechanized fasteners for its hydrostocksMining equipment and electromechanics3, 2834 (2016).

4. L.F. Kozhukhov, V.S. Barinov, R.P. Zhuravlev. Investigation of interaction of the mechanized fasteners with the side rocks at regulation of the initial arrangement (in Russian) Adaptivity of the mechanized fasteners. Problems of rock pressure 41, 52-55 (1983).

5. A I Potapov, A I Shikhov, E N Dunaeva, Geotechnical monitoring of frozen soils: problems and possible solutions IOP Conf. Ser.: Mater. Sci. Eng.1064 (2021).

6. B. K. Myshlyaev. The main directions of development of mechanized fasteners for slanting beds Problems of Mountain Pressure: a collection of scientific articles 47, 39 (1989).

7. G. Stepanovich. Application of pneumatic balloon mountings on steep formations of Donbass (1977).

8. V.N. Poturaev, A.G. Chervonenko, N.N. Kharchenko. Pneumo-balonnaya shoring applicant and patentee of the USSR (1980).

9. A.M. Dolinskiy. Mechanized fastener section Applicant and patentee of the USSR (1978).

10. O.V. Kolokolov, V.S. Rakhutin, E.A. Fedorenko, T.A. Saksaganskiy, I.S Romanenko. Pneumatic support section (its variants) Applicant and patentee of the Dnepropetrovsk 
Red Banner of Labor Mining Institute (1982).

11. V. Gabov, D. Zadkov, N. Babyr, V. Buevich, A. Stebnev. Section of mechanized support with guide and support beams Applicant and patentee of St. Petersburg Mining University (2017).

12. A I Shikhov, A I Potapov The pattern of changes in the velocity of propagation of ultrasonic waves in frozen soil samples during thawing, J. Phys.: Conf. Ser.1582 (2020).

13. Yu. Lykov et al. Investigation of the suitable dimensions for hydraulic prop support of self-advancing hydraulic roof support in underground mining at QuangNinh coal basin in Viet Nam. J. Phys.: Conf. Ser. 1753 (2021).

14. Stebnev, A.V., Buevich, V.V. Improvement of performance indicators of hydraulic drive of props of powered support units of heading complexes Journal of Mining Institute 227, 576-581 (2017). 